\title{
Effect of Intron Mutations on Processing and Function of Saccharomyces cerevisiae SUP53 tRNA In Vitro and In Vivo \\ MARJORIE C. STROBEL ${ }^{1.2+}$ AND JOHN ABELSON ${ }^{1 *}$ \\ Division of Biology, 147-75, California Institute of Technology, Pasadena, California 91125, ${ }^{1}$ and Biology Department, University of California, San Diego, La Jolla, California 920932
}

Received 4 December 1985/Accepted 2 April 1986

\begin{abstract}
The Saccharomyces cerevisiae leucine-inserting amber suppressor tRNA gene SUP53 (a tRNA Leu allele) was used to investigate the relationship between precursor tRNA structure and mature tRNA function. This gene encodes a pre-tRNA which contains a 32-base intron. The mature tRNA ${ }^{\text {SUP53 }}$ contains a 5-methylcytosine modification of the anticodon wobble base. Mutations were made in the SUP53 intron. These mutant genes were transcribed in an $S$. cerevisiae nuclear extract preparation. In this extract, primary tRNA gene transcripts are end-processed and base modified after addition of cofactors. The base modifications made in vitro were examined, and the mutant pre-tRNAs were analyzed for their ability to serve as substrates for partially purified $S$. cerevisiae tRNA endonuclease and ligase. Finally, the suppressor function of these mutant tRNA genes was assayed after their integration into the $S$. cerevisiae genome. Mutant analysis showed that the totally intact precursor tRNA, rather than any specific sequence or structure of the intron, was necessary for efficient nonsense suppression by tRNA ${ }^{\text {SUPS3 }}$. Less efficient suppressor activity correlated with the absence of the 5-methylcytosine modification. Most of the intron-altered precursor tRNAs were successfully spliced in vitro, indicating that modifications are not critical for recognition by the tRNA endonuclease and ligase.
\end{abstract}

Intervening sequences (IVS), or introns, have been found in the genes which encode the major classes of eucaryotic RNA, both nuclear and organellar. Recently, the mechanisms by which introns are removed from the primary RNA transcript have been the focus of intense investigation (reviewed in references 7,14 , and 51). However, relatively few experiments have elucidated a biological function for an IVS separate from the role of intron sequence or structure in the splicing process.

Saccharomyces cerevisiae affords an ideal system for investigating intron function. A number of yeast nuclear mRNA and tRNA genes containing introns have been cloned. These genes can be mutated in vitro and the mutant phenotype assayed by introducing the mutated genes into yeast cells by chromosomal integration. Using these methods, $\mathrm{Ng}$ et al. (40) showed that precise removal of the $S$. cerevisiae actin gene intron did not affect the production of actin mRNA or actin protein in vivo. Cells containing only the intron-deleted actin gene exhibit a normal growth rate and normal meiotic products upon sporulation.

In contrast, Johnson and Abelson (22) found that precise removal of the intron from an $S$. cerevisiae suppressor tRNA gene has profound effects on the phenotype of the mature suppressor tRNA product. Comparing strains containing the tyrosine-inserting ocher suppressor tRNA ${ }^{S U P 6}$ and its introndeleted counterpart SUP6 32 , they found that SUP6 $\Delta 32$ was inefficient in suppressing ocher nonsense mutations. When in vivo-labeled tRNA ${ }^{\text {Tyr }}$ from the two strains was examined, SUP6-specific RNA from the deletion strain lacked a pseudouridine $(\psi)$ base modification normally found on the central uridine of the UUA anticodon. These data suggest that the IVS-containing precursor, by virtue of either

\footnotetext{
* Corresponding author.

† Present address: LBI-Basic Research Program, National Cancer Institute-Frederick Cancer Research Facility, Frederick, MD 21701.
}

its total structure or some specific feature of the IVS itself, is recognized as the appropriate substrate for this pseudouridylation enzyme.

In this study we are directly examining the role of intron sequence and structure on precursor tRNA processing and mature tRNA function. The $S$. cerevisiae tRNA gene $S U P 53$ (a tRNA ${ }_{3}^{\text {Leu }}$ allele) encodes a leucine-inserting, amber suppressor tRNA. Pre-tRNA ${ }^{\text {SUPS3 }}$ contains a 32-base intron. Intron-mutated genes were constructed and transcribed in vitro. These transcripts were analyzed for base modifications and for their ability to be spliced in vitro. Finally, the in vitro phenotype of each mutant was correlated with its in vivo suppressor function after integration into the $S$. cerevisiae genome.

The results show that the entire intron, or the total precursor tRNA structure, is required for efficient suppressor function of the resultant mature tRNA. The reduced suppressor phenotype is correlated with lack of a 5methylcytosine modification of the anticodon wobble base. However, undermodification of a precursor tRNA per se has no effect on its ability to serve as substrate for the $S$. cerevisiae endonuclease and ligase in vivo. In fact, most alterations in the intron, unless they perturb the overall structure of the precursor tRNA, do not impair splicing enzyme function.

\section{MATERIALS AND METHODS}

Strains, plasmids, and media. The sequence of $S$. cerevisiae SUP53 precursor and mature tRNAs is shown in Fig. 1. $S U P 53$, an amber suppressor allele of tRNA ${ }_{3}^{\text {Leu }}$, is located on the left arm of $S$. cerevisiae chromosome III, closely linked to the $L E U 2$ marker $(1,10,31)$. The SUP53 gene was cloned by gene replacement into the yeast integrative plasmid YIpLEU2 (YIpLEU2SUP53, kindly provided by A. Newman [39]). To assess their in vivo function, SUP53 and mutant genes cloned in YIpLEU2 were introduced into $S$. cerevisiae SL183-21C [ $\alpha$ met8-1(Am) tyr7-l(Am) trpl-l(Am) 
A

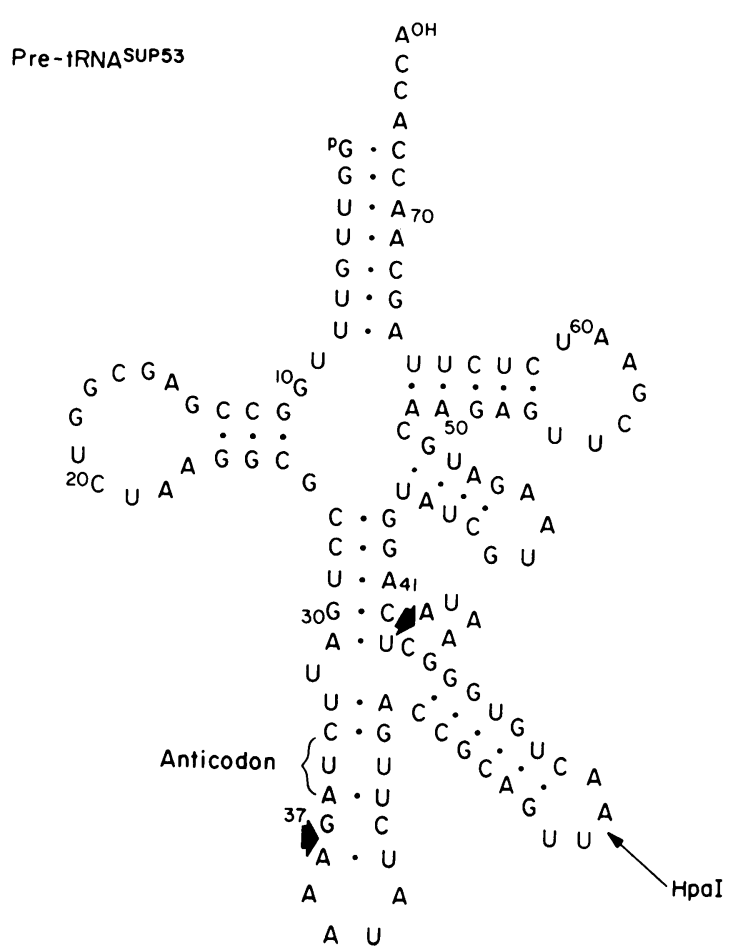

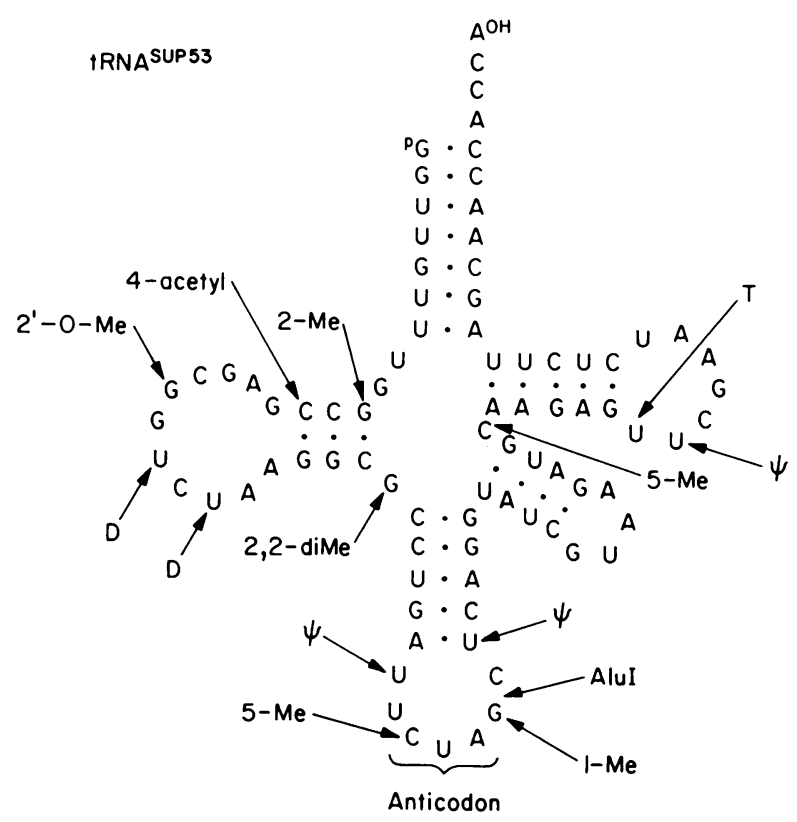

Anticodon

FIG. 1. Structure of precursor and mature species of tRNA ${ }^{\text {SUP53 }}$. (A) Structure of pre-tRNA ${ }^{\text {SUPS3 }}$. The 32-base intron is delineated by the large arrows. The HpaI restriction enzyme site, located within the intron of the SUP53 gene, is shown. Numbering of the mature domain is by the convention established for tRNA ${ }^{\text {Phe }}$. (B) Cloverleaf structure of the mature tRNA ${ }^{\text {SUPS3 }}$, including nucleoside modifications. The AluI restriction enzyme site created in the SUP53 IIVS mutant gene is shown. This site precisely divides the SUP53 IVS gene into 5'-half and $3^{\prime}$-half genes. Abbreviations for nucleoside modifications: Me, methyl; $2^{\prime}-O$-Me, $2^{\prime}-O$-methyl; diMe, dimethyl; $\psi$, pseudouridine; and T, ribothymidine.

ade3-26(Am) ilv1-1(Am) leu2-1(Oc) lys2-1(Oc) $c^{2}{ }^{\mathrm{R}} 1$ 132(Am), kindly provided by S. Liebman].

Yeast cultures were routinely grown in YPD medium. $\mathrm{Leu}^{+}$yeast transformants were assayed on drop-out plates of synthetic complete medium minus leucine. Suppressor tRNA function of $\mathrm{Leu}^{+}$transformants was assayed on drop-out plates of synthetic complete medium minus tryptophan. All yeast media were made by the formulations of Sherman et al. (52).

A 772-base-pair (bp) AluI fragment of YIpLEU2SUP53, containing the entire tRNA gene and the $5^{\prime}$ terminus of the LEU2 gene, was subcloned into the SmaI site of M13mp8, kindly provided by A. Newman (39) (Fig. 2A). M13SUP53 (Fig. 2B) and the in vitro mutagenesis-derived M13SUP53 $\Delta$ IVS (Fig. 2C) were used in additional mutant constructions described below. Recombinant molecules in which the vector sequences were provided by M13 were transformed into Escherichia coli JM101 [ $\Delta$ (lac-pro) supE thi $\mathrm{F}^{\prime}$ traD36 proAB lac ${ }^{\mathbf{q}} Z \Delta M 15$; J. Messing, personal communication].

Preparatory to introducing SUP53 or its mutant derivatives into yeast cells, the small AvaI-BstEII fragment from M13 clones was subcloned into YIpLEU2 linearized with $A v a I$ and BstEII (Fig. 2). The resident tRNA ${ }_{3}^{\text {Leu }}$ of YIpLEU2 was replaced with the appropriate SUP53 allele, and the LEU2 gene was reconstructed. YIpLEU2, YIpLEU2 SUP53, and the mutant derivatives were transformed into $E$. coli $\mathrm{HB} 101\left(\mathrm{~F}^{-}\right.$hsdS20 recAl3 ara-14 proA2 lacYl galK2 rpsL20 xyl-5 mtl-1 supE44 $\lambda^{-}$) (5).

Bacterial cultures were grown in YT medium for M13 phage or YT medium plus ampicillin (Polycillin; 40 to 60 $\mu \mathrm{g} / \mathrm{ml}$ ) for YIpLEU2-derived plasmids. All bacterial media were made as described by Miller (36).

All restriction endonucleases were obtained from commercial sources (Bethesda Research Laboratories, Gaithersburg, Md.; New England Biolabs, Beverly, Mass.; Boehringer Mannheim, Indianapolis, Ind.) and used under the reaction conditions recommended by the manufacturers.

Mutant construction. The SUP53 mutants investigated in this study are shown in Fig. 3. These mutants were made either by oligonucleotide-directed mutagenesis, by the ligation of half-tRNA genes, or by cloning of complementary oligonucleotides. All mutants were initially constructed in M13mp8 or mp10 and subsequently transferred into YIpLEU2 (Fig. 2).

The $\triangle I V S$, anticodon base-pairing (ACBP), and insert (INS) mutants were constructed by oligonucleotide-directed mutagenesis as previously described (39). $\Delta 3^{\prime}$ IVS and $\Delta 5^{\prime}$ IVS were made by ligating half-tRNA genes generated by cutting SUP53 at the unique HpaI site (Fig. 1A and 2B) and SUP $53 \Delta$ IVS by cutting at a unique intragenic AluI site (Fig. $1 \mathrm{~B}$ and 2C). The SUP53 clone was triply digested with

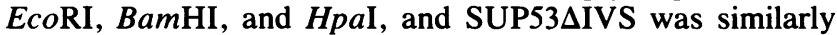
cut with EcoRI, BamHI, and AluI. These digests were resolved on $6 \%$ acrylamide gels. The appropriate bands were excised from the gel and crush-eluted overnight at $37^{\circ} \mathrm{C}$. The isolated EcoRI-HpaI and AluI-BamHI or EcoRI-AluI and $H p a I-B a m H I$ fragments were ligated into M13mp10 linearized with EcoRI and BamHI, creating $\Delta 3^{\prime} \mathrm{IVS}$ and $\Delta 5^{\prime} \mathrm{IVS}$, 
A

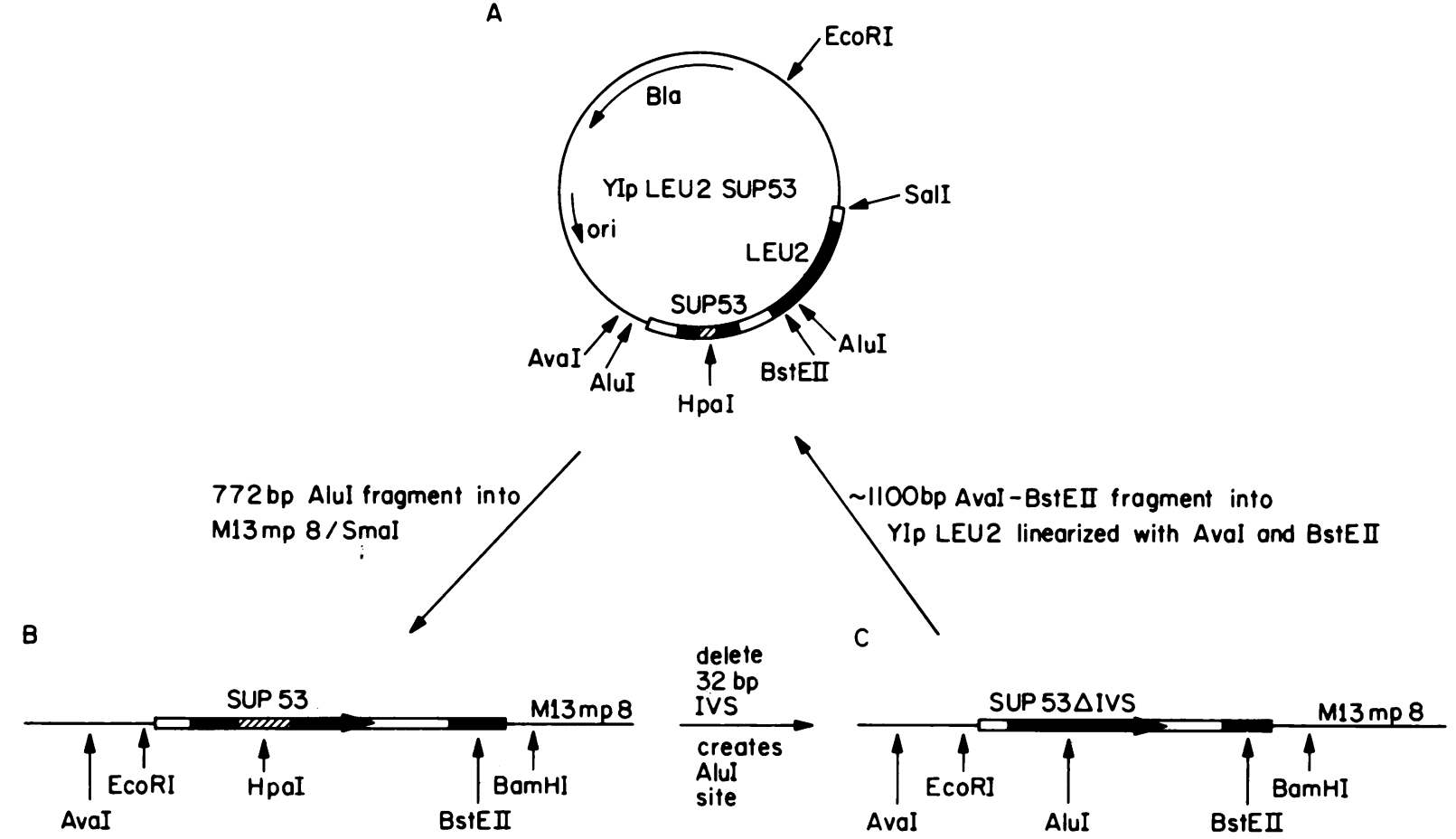

FIG. 2. General strategy for construction of SUP53 mutants and their introduction into the S. cerevisiae integration vector YIpLEU2. YIpLEU2SUP53 (A) was constructed by replacement of the tRNA ${ }_{3}^{\text {Leu }}$ gene normally present on the yeast integration vector YIpLEU2 with its amber suppressor allele SUP53. M13SUP53 (B) was constructed by cloning the 772-bp AluI fragment of YIpLEU2SUP53 into the unique SmaI site of M13mp8. M13SUP53AIVS (C) was made by oligonucleotide-directed deletion of the 32-bp intron of SUP53, as described in Materials and Methods. The SUP53 $\triangle$ IVS and additional mutant genes were introduced into the YIpLEU2 vector by isolation of the $\sim 1,100$-bp

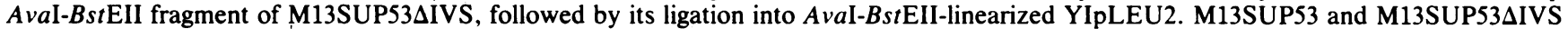
were used for the construction of additional mutants in the M13mp8 or mp10 vector (see Fig. 3). For introduction into yeast cells, YIpLEU2 containing SUP53 or a mutant derivative was linearized with AvaI and SaII. The small AvaI-SalI fragment contained both the tRNA gene and the $L E U 2$ marker.

respectively. Molecular cloning procedures were those described by Maniatis et al. (32).

By using the unique intragenic AluI site of SUP53 2 IVS (Fig. $1 \mathrm{~B}$ and $2 \mathrm{C}$ ), the Alu $5 \rightarrow 3$ mutant (Fig. 3) was constructed by cloning complementary oligonucleotides. The 5 '-hydroxyl oligonucleotides were mixed in equimolar amounts and annealed in $6 \mathrm{mM}$ Tris chloride $(\mathrm{pH} 7.9)-50$

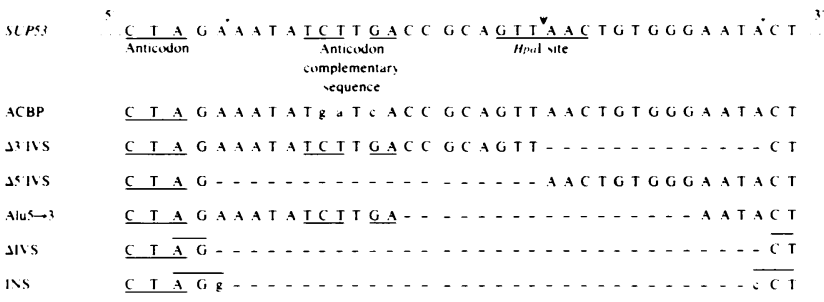

FIG. 3. Sequences of SUP53 intron mutants. The sequences of the various SUP53 intron mutants examined are shown. Their construction is described in detail in Materials and Methods. Arrows indicate the position of the SUP53 32-bp intron. Underlined sequences indicate the anticodon (CTA), the intron sequence complementary to the anticodon (TCTTGA), and the unique, intronic $\mathrm{HpaI}$ restriction enzyme site (GTTAAC). The small arrow indicates the site of the HpaI enzyme cut. Lowercase letters show the base changes introduced by oligonucleotide-directed mutagenesis. Overlined sequences point out the unique, intragenic AluI (AGCT) and StuI (AGGCCT) restriction enzyme sites created in the $\Delta$ IVS and INS mutants, respectively.
$\mathrm{mM} \mathrm{NaCl}-6 \mathrm{mM} \mathrm{MgCl}{ }_{2}$ by heating to $80^{\circ} \mathrm{C}$ followed by slow cooling to room temperature. As described above, halftRNA genes were isolated from SUP53 $\triangle$ IVS DNA. These restriction fragments and annealed oligonucleotides were ligated into M13mp10 linearized with EcoRI and BamHI. Positive plaques were identified as previously described (39).

Synthetic oligonucleotides were kindly provided by B. Kaplan (City of Hope, Duarte, Calif.) and S. Horvath, Carol Graham, and M. Tomich (California Institute of Technology). All oligonucleotides were purified on $20 \%$ acrylamide-7 M urea gels. The sequence of all SUP53 mutant genes was confirmed by DNA sequencing by the method of Sanger et al. (50) with a SUP53-specific oligonucleotide primer. Replicative-form DNA was prepared by the alkaline lysis method (3).

In vitro transcription. A yeast nuclear extract preparation (YNE) (9) was used to transcribe in vitro SUP53 and derivative mutant genes. This extract contains the enzyme activities to synthesize the primary transcript of a tRNA gene; to end-process this transcript, generating mature 5' and $3^{\prime}$ ends; to effect specific base modifications in the presence of appropriate cofactors; and to add the 3 '-terminal CCA nucleotides.

Transcription reactions were carried out essentially by the method of Newman et al. (39). The precise amounts of YNE and template used in each reaction were optimized by titration of the given YNE preparation. To study base methylations effected by activities present in YNE, the methyl donor $S$-adenosyl-L-methionine (SAM; $p$-tolu- 


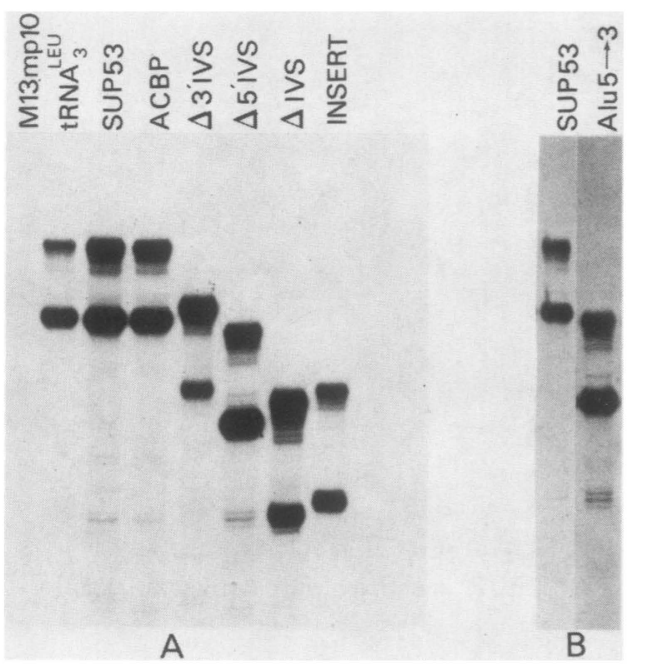

FIG. 4. In vitro transcription of SUP53 and mutants. The [ $\alpha-$ $\left.{ }^{32} \mathrm{P}\right] U T P$-labeled products of SUP53 and mutant DNAs transcribed in vitro are shown. All transcription templates were replicative-form DNA of the tRNA gene cloned in a M13 vector. Panels A and B represent different transcriptional mixes with the same YNE preparation. The larger band in each track represents the primary transcript of each gene, containing $\sim 10$ nucleotides of $5^{\prime}$ and $\sim 5$ nucleotides of $3^{\prime}$ extension plus the mature domain (and IVS). The smaller dominant band(s) is the end-processed transcript from which these extensions have been removed and 3'-terminal CCA added posttranscriptionally. This secondary transcript is unspliced. Products were resolved on $8 \%$ polyacrylamide- $8 \mathrm{M}$ urea thin gels. Autoradiography was done as described in Materials and Methods.

enesulfonic acid salt, Sigma Chemical Co., St. Louis, Mo.) was added to the transcription cocktail $(0.02 \mathrm{mM})(6)$. The reaction mixes were incubated at $30^{\circ} \mathrm{C}$ for $15 \mathrm{~min}$ and processed as described previously (39). RNA products were resolved on $8 \%$ acrylamide $-7 \mathrm{M}$ urea or $10 \%$ acrylamide -4 $M$ urea gels. After visualization by autoradiography on Kodak XAR5 film (Eastman Kodak, Rochester, N.Y.) with Cronex Lightning-Plus intensifying screens (E. I. du Pont de Nemours, Inc., Wilmington, Del.), RNAs were passively eluted. Eluted RNAs were ethanol precipitated with the appropriate carrier $(20 \mu \mathrm{g}$ of tRNA or glycogen per $\mathrm{ml})$ prior to nucleotide analysis or in vitro splicing assays.

RNA analysis. Separation of modified nucleosides was done by the method of Saneyoshi et al. (49) as previously described (22). Since the in vitro-synthesized RNA was radiolabeled with a single ribonucleoside triphosphate, the base modifications at given positions could be investigated by digestion with different RNases. RNases $T_{1}, T_{2}$, and $A$ (pancreatic) produce nucleoside-3'-monophosphates, and the labeled phosphate is derived from a nearest-neighbor transfer, whereas nuclease $\mathrm{P} 1$ produces nucleoside-5'monophosphates, and the labeled phosphate remains with its input nucleotide. All RNases were obtained from Calbiochem, La Jolla, Calif., and used as previously described (22).

In vitro splicing assays. To investigate the suitability of SUP53 mutants as substrates for $S$. cerevisiae tRNA endonucleases and ligase, in vitro-transcribed RNAs were used in cutting and ligation assays $(15,16,45 a)$. Equal amounts of radioactivity of each RNA precursor were used in comparable cutting or cutting-ligation assays. These RNAs were derived from a single transcription reaction cocktail and were assumed to have similiar radioisotopic specific activity.

Partially purified yeast endonuclease (fraction VI; DEAE fractions 26 through 29; approximately 800-fold purified; kindly provided by C. Peebles [45]) and yeast ligase (fraction IV, heptyl-agarose pool; approximately 300 - to 400 -fold purified; kindly provided by C. Greer and E. Phizicky [16, 45a]) were used at dilutions which had been determined to give $50 \%$ cutting of the SUP53 precursor by endonuclease (1 $\mu l$ of a 1:30 dilution per $10-\mu$ l reaction mixture) and virtually $100 \%$ ligation of the resultant half-molecules by ligase $(2 \mu \mathrm{l}$ of a 1:50 dilution per 10- $\mu$ l reaction mixture) in $20 \mathrm{~min}$ at $30^{\circ} \mathrm{C}$. After incubation the reaction mixes were processed as described previously (39). Products were resolved on $10 \%$ acrylamide $-4 \mathrm{M}$ urea gels.

The identity of RNA products was based on their size and their appearance and disappearance under appropriate conditions. In several cases, their identity was confirmed by two-dimensional separation of RNase $T_{1}$ oligonucleotides (data not shown).

Yeast transformation. SUP53 and mutant derivatives cloned in the yeast integration plasmid YIpLEU2 were introduced into $S$. cerevisiae SL183-21C by the method of Ito et al. (19). Because of the close linkage between the SUP53 locus and the $L E U 2$ marker $(1,10,31)$, cells transformed with YIpLEU2SUP53 or mutant derivative DNAs linearized with $A v a$ I and SalI (Fig. 2A) can integrate both the SUP53 and LEU2 genes by homologous recombination (47). Transformants were initially screened for acquisition of a $\mathrm{Leu}^{+}$phenotype after growth for 3 to 4 days at $30^{\circ} \mathrm{C}$.

Suppression testing. To assay the presence and function of SUP53 and mutant derivatives, $\mathrm{Leu}^{+}$transformants were tested for their ability to grow on synthetic yeast medium minus tryptophan by the method of Shaw and Olson (52). Of the six amber-suppressible nonsense mutations in SL183-21C, the trpl-1(Am) marker was found to clearly discriminate the suppressor strength of the tRNA encoded by the SUP53 allele (data not shown). Briefly, individual $\mathrm{Leu}^{+}$transformants were grown overnight in YPD medium and then washed and suspended in water to $1 \mathrm{OD}_{660} / \mathrm{ml}(\sim 2$ $\times 10^{7}$ cells per ml). Serial dilutions $\left(10^{6}\right.$ to $10^{3}$ cells per $\left.\mathrm{ml}\right)$ were made in water. A 5 - $\mu$ l amount of each dilution $\left(10^{5}\right.$ to $10^{1}$ cells) was spotted on tryptophan drop-out plates. Plates were scored for growth after 3 to 4 days at $30^{\circ} \mathrm{C}$. Twenty to $30 \mathrm{Leu}^{+}$transformants from two independent yeast transformations with each tRNA gene were assayed for suppressor function. In each group of $\mathrm{Leu}^{+}$transformants, at most $20 \%$ of the transformants showed no growth in the absence of tryptophan, indicating that the suppressor tRNA gene probably was not introduced by the transplacement event. Quantification of suppressor function was based only on the Leu ${ }^{+}$ transformants which grew on tryptophan drop-out plates. The parent strain, SL183-21C, exhibited no growth in the absence of tryptophan.

\section{RESULTS}

Mutant construction. Figure 3 shows the sequences of the SUP53 intron mutations. The ACBP mutant contained three base changes which interrupted the conserved base-pairing in the precursor TRNA between an intron sequence and the anticodon (43). The INS mutant had a 2-base "intron" introduced. Four mutant genes contained total or partial deletions of intron sequences ( $\Delta$ IVS, $\Delta 3^{\prime}$ IVS, $\Delta 5^{\prime}$ IVS, and Alus $\rightarrow 3$ ).

The $\Delta$ IVS mutant contained a total deletion of the 32-base intron. As such, tRNA ${ }^{\Delta I V S}$ had the same sequence and, 


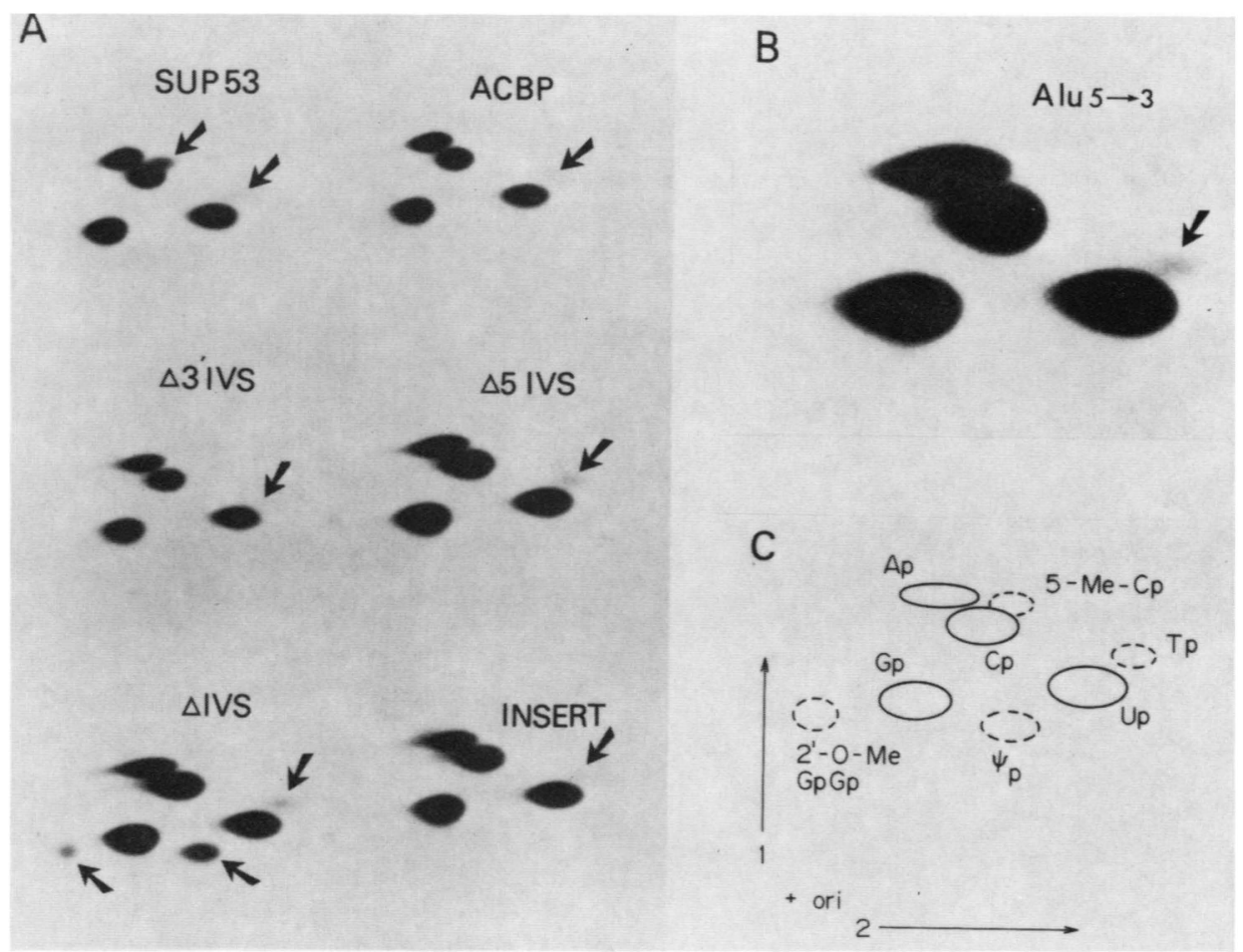

FIG. 5. Modified-nucleotide analysis of SUP53 and mutant transcripts made in vitro in the presence of $\left[\alpha-{ }^{32} \mathrm{P}\right] \mathrm{UTP}$ and SAM. End-processed tRNAs were recovered from the transcription gel as described in Materials and Methods. Labeled RNA, in the presence of $20 \mu \mathrm{g}$ of carrier tRNA, was digested with RNase $T_{2}, R$ Nase $T_{1}$, and RNase A. Nucleoside-3'-monophosphates, labeled by nearest-neighbor transfer from [ $\left.\alpha{ }^{-32} \mathrm{P}\right] \mathrm{UTP}$, were resolved as described in Materials and Methods. (A and B) Chromatograms of SUP53 and mutant RNAs. Arrows indicate modified nucleotides. The tRNAs in panel A are the products of a single transcription cocktail. The tRNA in panel B represents an independent transcription with the same YNE preparation. (C) Cartoon identifying the nucleotide-3'-monophosphates. A single dinucleotide $\left(2^{\prime}-O-M e-G p G p\right)$ was seen. The presence of the methyl group on the $2^{\prime}$-hydroxyl rendered this linkage insensitive to the nucleases used. Arrows indicate the direction of chromatography. See the legend to Fig. 1 for abbreviations.

presumably, structure as mature tRNA ${ }^{\text {SUPS3 }}$. $\triangle 5^{\prime}$ IVS pretRNA had a deletion of the first 19 bases of the intron. The Alu $5 \rightarrow 3$ mutant encoded a 15 -base intron which retained the normal sequence at intron-exon boundaries and the conserved complementarity between the intron and the anticodon. $\Delta 3^{\prime}$ IVS contained a 19 -base intron with altered sequence at the $3^{\prime}$ intron-exon junction, while retaining the SUP53 sequence at the $5^{\prime}$ splice junction.

Transcription of SUP53 intron mutants. The SUP53 and intron-mutated genes were transcribed in vitro by using YNE (9). This extract contains the activities required to transcribe tRNA genes (polymerase III and associated factors), end-process the primary transcript, posttranscriptionally add the 3 '-terminal CCA, and introduce base modifications (in the presence of appropriate cofactors). While this extract contains the activities needed to remove introns and ligate tRNA exons, splicing proceeds inefficiently under the salt conditions optimal for transcription. Splicing of the pre-tRNAs was examined with partially purified tRNAsplicing enzymes (see Fig. 8).

Figure 4 shows the transcription products of each mutant gene made in the presence of $\left[\alpha{ }^{32}\right.$ P $]$ UTP. The largest band(s) was the primary gene transcript, whereas the smaller band(s) contained the RNA from which the $\sim 10$ nucleotides of $5^{\prime}$ and $\sim 5$ nucleotides of $3^{\prime}$ extensions have been removed. The small RNA(s) had at least partial terminal addition of CCA.

All mutants were transcribed efficiently. Also, except for $\Delta I V S$ and $\Delta 3^{\prime}$ IVS, the primary transcripts were efficiently end-processed (Fig. 4) (D. Engelke, personal communication). In several tracks, faint band(s) comigrated by size with end-processed $\Delta I V S$ RNA(s). These bands probably represent the products of splicing.

Analysis of the anticodon wobble base modification. Based on the previous observation that deletion of the IVS from the SUP6 gene resulted in no modification of an anticodon nucleotide, attention was focused on potential modifications of the wobble base cytosine $\left(\mathrm{C}_{34}\right)$ in the SUP53 CUA anticodon. This nucleotide is known to be a 5-methylcytosine in tRNA ${ }_{3}^{\text {Leu }}$ in vivo (Fig. 1B) $(23,55)$.

The SUP53 and mutant DNAs were transcribed in the presence of $\left[\alpha-{ }^{32}\right.$ P]UTP and the methyl donor SAM. Mature SUP53 RNA contained two 5-methylcytosine modifications $\left(\mathrm{C}_{34}\right.$ and $\left.\mathrm{C}_{48}\right)$ (Fig. 1B). However, transcripts labeled with $\left[\alpha-{ }^{32}\right.$ P]UTP and digested with RNases which effect nearestneighbor transfer of the $\alpha$-position phosphate labeled only the potentially modified wobble base cytosine $\left(C_{34}\right)$.

End-processed RNAs were excised from the transcription gel and digested with RNases $T_{1}, T_{2}$, and $A$. Nucleosides were resolved in a two-dimensional chromatographic system that separates modified nucleosides from their unmodified counterparts $(22,49)$. The autoradiograms of the products derived from pre-tRNA ${ }^{S U P 53}$ and mutant RNAs is shown in Fig. 5. Only the SUP53 RNA contained the expected 5methylcytosine modification. None of the six mutants had any detectable cytosine modifications. Except for the $\Delta I V S$ mutant, they showed only limited amounts of ribothymidine, derived from modification of $\mathrm{U}_{54}$ to $\mathrm{T}_{54}$ (Fig. 1). The limited 


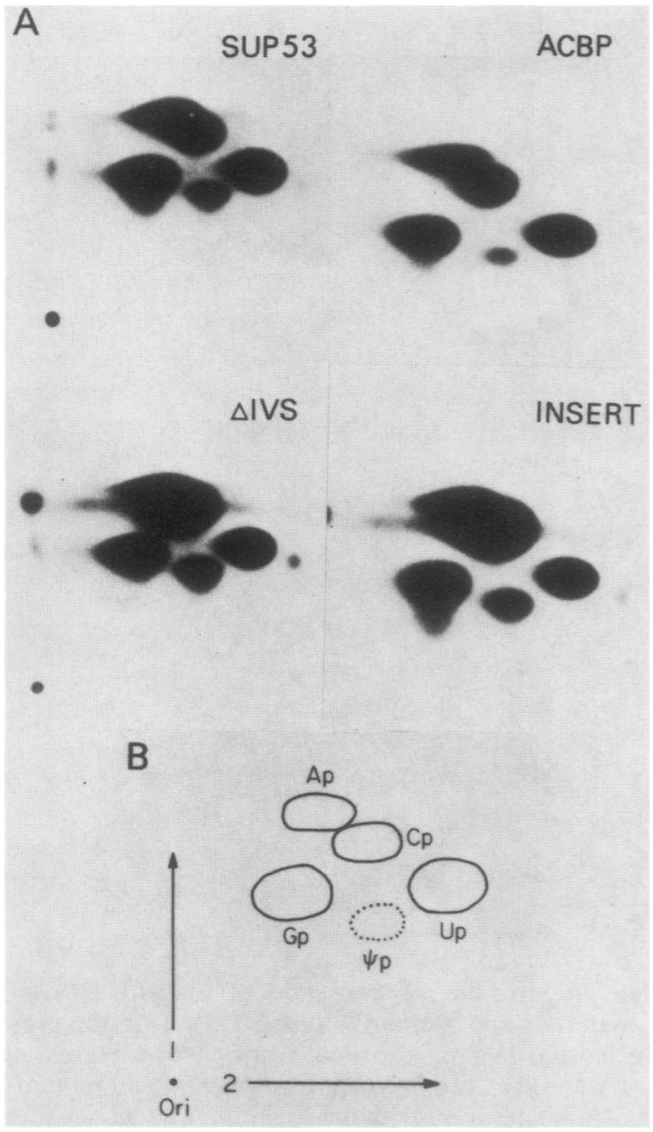

FIG. 6. Modified-nucleotide analysis of SUP53 and mutant transcripts made in vitro in the presence of $\left[\alpha-{ }^{32} \mathrm{P}\right] \mathrm{CTP}$ and SAM. End-processed tRNAs, made in vitro in the presence of $10 \mu \mathrm{Ci}$ of $\left[\alpha-{ }^{32} \mathrm{P}\right] \mathrm{CTP}$ and $0.02 \mathrm{mM}$ SAM, were digested and chromatographed as described in Materials and Methods. (A) Chromatograms of SUP53 and mutant RNAs. A single modified nucleotide-3'monophosphate (pseudouridine $[\psi \mathrm{p}]$ ) was found in all digests. All tRNAs are the products of a single transcription cocktail. (B) Cartoon identifying the nucleotide-3'-monophosphates. Arrows indicate the direction of chromatography. See the legend to Fig. 1 for other abbreviations.

amount of ribothymidine presumably reflects inefficient $U$ to-T modification in this system.

In addition to $\mathrm{T}_{54}$, the $\triangle \mathrm{IVS}$ mutant RNA contained two other modified nucleotides not seen in the SUP53 precursor: 2 '- $O$-methyl-G and pseudouridine $(\psi)$, presumably representing positions 18 and 32, respectively (Fig. 1). The 2 '-O-methylation of the ribose sugar is a modification found only in mature tRNAs $(17,48)$. In contrast, the INS mutant, which differed from $\triangle I V S$ only by the inclusion of a 2-base intron (or 2-base insertion in the mature tRNA anticodon loop) did not exhibit either modification. Therefore, $\Delta$ IVS is apparently being recognized as a mature tRNA, while the INS mutant RNA is not.

Comparison of base modifications made in two precursor and two mature tRNAs. Any alteration in the structure of SUP53-derived precursor tRNA resulted in a lack of the expected anticodon modification. Furthermore, insertion of 2 bases into the anticodon loop severely altered the detected modification pattern of a "mature" tRNA. Therefore, these mutants provide a means of investigating the substrate requirements of the enzymes which effect other base modi-

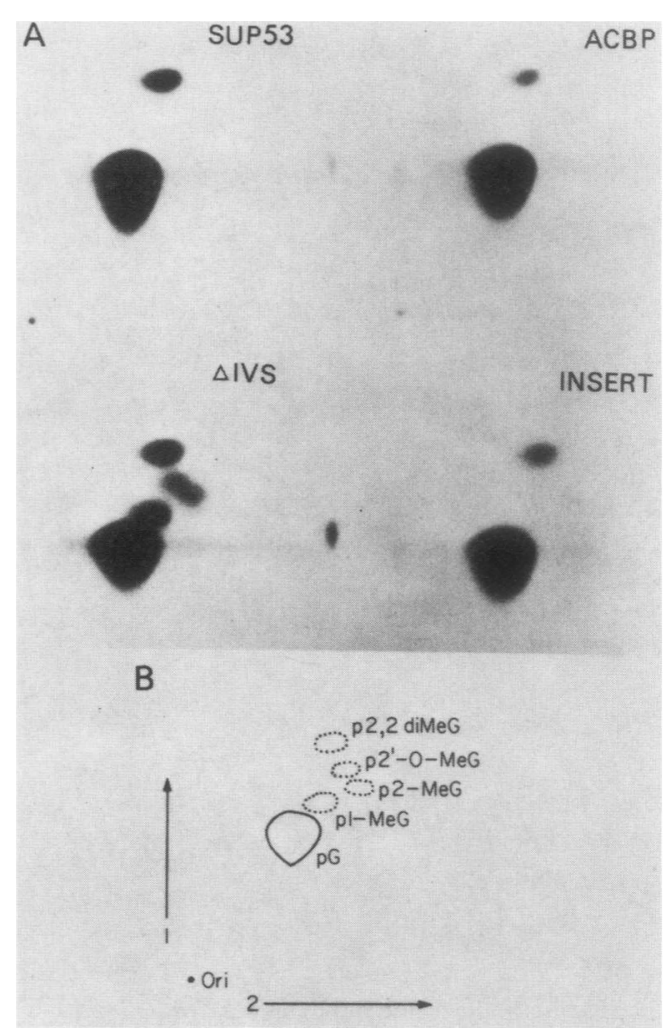

FIG. 7. Modified-nucleotide analysis of SUP53 and mutant transcripts made in vitro in the presence of $\left[\alpha-{ }^{32} \mathrm{P}\right] \mathrm{GTP}$ and SAM. End-processed tRNAs were recovered from the gel as described in Materials and Methods. Labeled RNA, in the presence of $20 \mu \mathrm{g}$ of carrier tRNA, was digested with nuclease P1. The resulting nucleotide-5'-monophosphates were resolved as described in Materials and Methods. (A) Chromatograms of SUP53 and mutant RNAs. Since nuclease P1 yields nucleotide-5'-monophosphates, the $\alpha{ }^{32} \mathrm{P}$ label remains with the input nucleotide. SUP53, ACBP, and INS mutant RNAs showed only a single modified nucleotide-5' monophosphate (p-2,2-dimethyl-G). All tRNAs were the products of a single transcription cocktail. (B) Cartoon identifying the unmodified and modified 5'-GMPs. Arrows indicate the direction of chromatography. See the legend to Fig. 1 for abbreviations.

fications in SUP53 RNA. The SUP53, ACBP, $\triangle \mathrm{IVS}$, and INS RNAs were examined for additional nucleoside modifications.

SUP53 and the three derivatives were transcribed in vitro in the presence of either $\left[\alpha-{ }^{32} \mathrm{P}\right] \mathrm{CTP}$ or $\left[\alpha^{-32} \mathrm{P}\right] \mathrm{GTP}$. The $\left.{ }^{32} \mathrm{P}\right] \mathrm{CTP}$-labeled, end-processed RNAs were cleaved with RNases which effect nearest-neighbor transfer of the labeled phosphate (Fig. 6). The $\left[\alpha{ }^{32}\right.$ P]GTP-labeled RNAs were digested with nuclease $\mathrm{P1}$, generating $5^{\prime}$-monophosphates and leaving the $\alpha$-phosphate with the input nucleoside (Fig. 7). The only potentially modified bases which were not investigated were $\mathrm{C}_{12}$ (4-acetyl-C) and $\mathrm{U}_{19,21}$ (dihydrouridine) (Fig. 1).

Figure 6 shows the nucleotides labeled by nearestneighbor transfer from $\left[\alpha{ }^{32} \mathrm{P}\right] \mathrm{CTP}$. All four RNAs contained pseudouridine as the sole detectable modified nucleotide, representing the expected $\mathrm{U}$ to $\psi$ modifications at positions 39 and 55 (Fig. 1). Precise modification at each position could not be discriminated. Expected modifications of $G_{10}$ and $G_{27}$ (Fig. 1) could not be seen by this strategy since these modified nucleotides comigrated with $\mathrm{Cp}$ and Ap. 
TABLE 1. Base modification of SUP53 and mutants in vitro ${ }^{a}$

\begin{tabular}{lcccc}
\hline \multicolumn{1}{c}{ Modified base $^{b}$} & SUP53 & ACBP & $\Delta$ IVS & INS \\
\hline 2-Methyl-G (10) & - & - & + & - \\
2'-O-Methyl-G (18) & - & - & + & - \\
2,2-Dimethyl-G (27) & + & + & + & + \\
\& (32) & - & - & + & - \\
5-Methyl-C (34) & + & - & - & - \\
1-Methyl-G (37) & - & - & + & - \\
\& (39, 55) & + & + & + & + \\
5-Methyl-C (48) & - & - & - & - \\
Ribothymidine (54) & + & + & + & + \\
\hline
\end{tabular}

${ }^{a}$ Compilation of data shown in Fig. 5 through 7 . In all cases, the data represent the results of several independent chromatographic separations with tRNAs derived from independent transcriptions. In some cases, the identity of spots was confirmed by examining their mobility in different chromatographic systems with different labeling and digestion strategies (data not shown). Under the general experimental protocol, modification of the pseudouridines $(\psi)$ at positions 39 and 55 could not be discriminated. All base modifications present in mature tRNA ${ }^{\text {SUPS3 }}$ (tRNA ${ }_{3}^{\text {Leu }}$ ) were examined except the 4-acetyl-C modification at position 13 and the dihydrouridine modifications at positions 19 and 21 (see Fig. 1).

${ }^{b}$ Numbers in parentheses indicate the position of the modified residue in mature tRNA ${ }^{\text {sUPS3 }}$, with the numbering convention established for yeast tRNA $^{\text {Phe }}$ (see Fig. 1).

Modified guanosine residues in SUP53 and the three mutants are shown in Fig. 7. All four RNAs contained 2,2-dimethylguanosine $\left(G_{27}\right.$, Fig. 1). Only the $\Delta I V S$ mutant contained othermodifiedGresidues: 2 -methyl-G, 2' - $O$-methylG, and 1-methyl-G (Fig. 1).
The expected modification of $\mathrm{C}_{48}$ to 5-methylcytosine (Fig. 1) was also examined (data not shown). This modification could not be clearly detected in any of the four RNAs examined. Previously, this modification was shown to be present in the tRNA ${ }_{3}^{\text {Leu }}$ precursor in vivo (23). Presumably, the inability to detect this modification is due to the in vitro system used.

Table 1 summarizes the chromatographic data of Fig. 5 through 7. Of the five examined modifications known to occur in pre-tRNA ${ }_{3}^{\text {Leu }}(23,55)$, the ACBP mutant differed only in the absence of the anticodon 5-methylcytosine. The INS mutant, an altered mature tRNA, was obviously undermodified compared with $\triangle I V S$.

In vitro splicing of pre-tRNA ${ }^{\text {SUP53 }}$ and derivative mutant pre-tRNAs. To investigate which, if any, intron features were critical for the splicing of a pre-tRNA, SUP53 and derivative mutants were tested for their ability to serve as substrates for the $S$. cerevisiae tRNA endonuclease and ligase. SUP53 and mutant genes were transcribed in vitro in the presence of $\left[\alpha-{ }^{32}\right.$ P]UTP and SAM. End-processed precursors were excised from the transcription gel and assayed with partially purified $S$. cerevisiae tRNA splicing enzymes (Fig. 8A and B). All tracks contained equal counts of precursor derived from a single transcription cocktail. Each pre-tRNA was assayed with endonuclease alone and endonuclease plus ligase. Both reactions were carried out in the presence of ATP and $\mathbf{M g}^{2+}$ (ligation conditions).

The SUP53, ACBP, $\Delta 5^{\prime}$ IVS, and Alu5 $\rightarrow 3$ RNAs were cut, as evidenced by the production of $3^{\prime}$ and $5^{\prime}$ half-molecules in

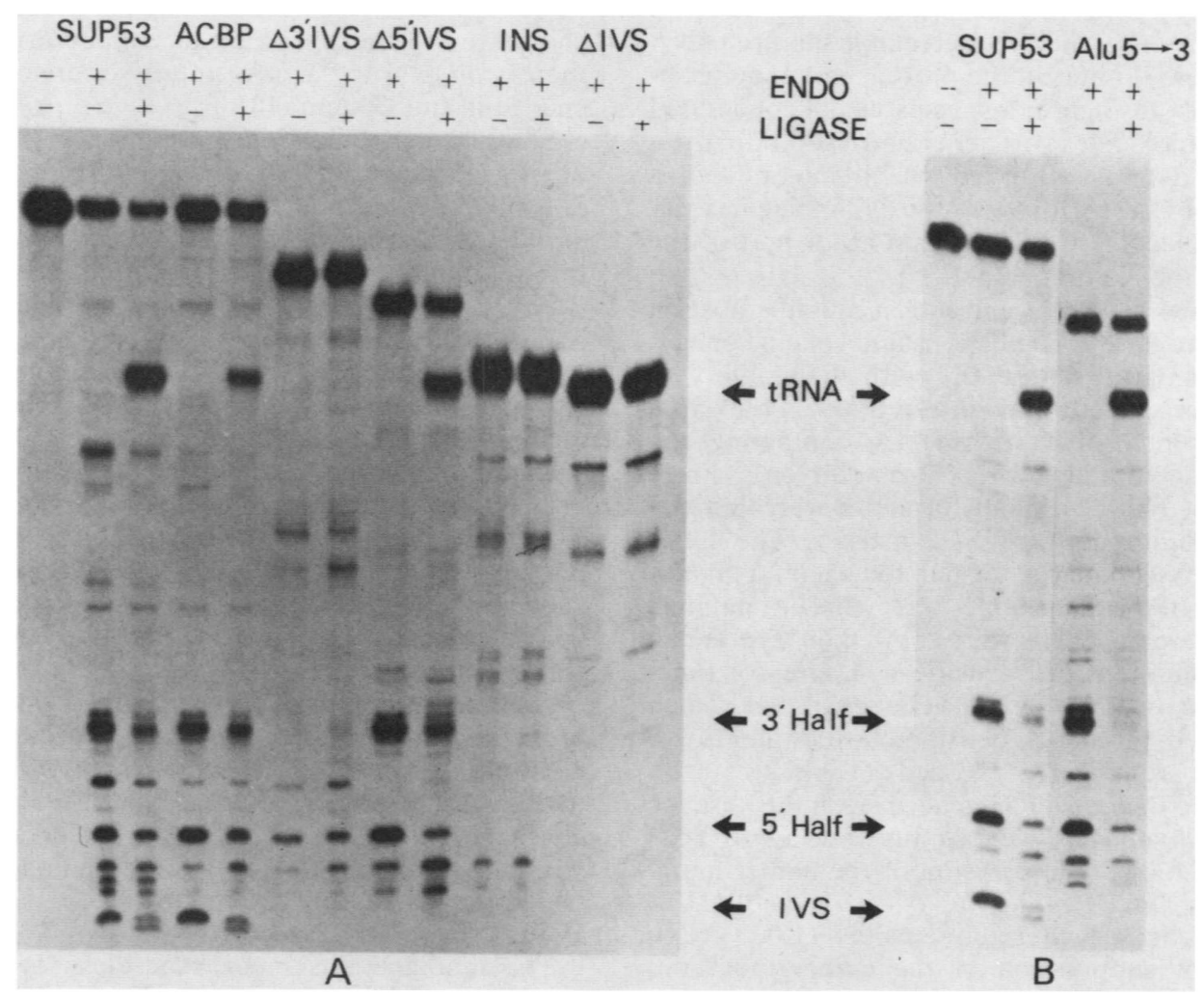

FIG. 8. In vitro splicing of SUP53 and intron mutant pre-tRNAs. Partially purified yeast tRNA endonuclease and tRNA ligase were used in splicing assays in the presence of $2 \mathrm{mM}$ ATP as described in Materials and Methods. In vitro-synthesized, end-processed pre-tRNAs labeled with $\left[\alpha{ }^{32} \mathrm{P}\right]$ UTP were recovered from a $10 \%$ polyacrylamide $-4 \mathrm{M}$ urea gel as described in Materials and Methods and were precipitated with $20 \mu \mathrm{g}$ of carrier glycogen. Since each panel represents the RNA derived from a single transcription cocktail, the specific activity of the RNAs were assumed to be virtually equal. Thus, equal Cerenkov counts of each pre-tRNA were used in each cutting or splicing reaction mixture. Reaction products were resolved on $10 \%$ polyacrylamide- $4 \mathrm{M}$ urea-TBE thin gels. 
TABLE 2. Suppressor function of SUP53 and intron mutants ${ }^{a}$

\begin{tabular}{lccc}
\hline tRNA & $\begin{array}{c}\text { 5-Methylcytosine } \\
\text { modification }\end{array}$ & Splicing & Suppression $^{b}$ \\
\hline SUP53 & Yes & Yes & +++++ \\
ACBP & No & Yes & +++ \\
Alu5 $\rightarrow 3$ & No & Yes & +++ \\
$\Delta 5^{\prime}$ IVS & No & Yes & +++ \\
$\Delta 3^{\prime}$ IVS & No & No (some cutting at & - \\
& & 5' junction) & ++ \\
$\Delta$ IVS & No & $-c$ & + \\
INS & No & No & - \\
\hline
\end{tabular}

${ }^{a}$ Suppressor function was quantified as described in Materials and Methods. S. cerevisiae SL183-21C was transformed with a linear restriction fragment containing both the tRNA gene and the $L E U 2$ marker (see Fig. 2). $\mathrm{Leu}^{+}$transformants were initially selected and tested for their ability to suppress the trpl-I(Am) marker as described in Materials and Methods. The quantification of suppressor fuction for SUP53 or mutants was based only on the transformants which grew in the absence of tryptophan, reflecting acquisition of the suppressor tRNA gene by transplacement.

${ }^{b}$ Strong suppressor $(+++++)$, Growth at low cell density $\left(10^{1}\right.$ cells $)$; weaker suppressor $(+++)$, growth only at higher cell density $\left(10^{3}\right.$ cells $)$; null suppressor ( - , no growth even at the highest cell density $\left(10^{5}\right.$ cells). SL183$21 \mathrm{C}$ exhibited no growth in the absence of tryptophan at any cell density. ${ }^{c}-, \Delta$ IVS contains no intron.

the presence of endonuclease. Furthermore, these halfmolecules were converted to mature-size tRNA with the addition of ligase. The $\triangle$ IVS and INS RNAs were not recognized by the splicing endonuclease as appropriate precursor tRNAs: neither mutant produced any detectable $3^{\prime}$ or 5' half-tRNA molecules.

The most startling result was seen with pre-tRNA ${ }^{\Delta 3^{\prime} I V S}$ The mutant RNA produced neither detectable mature tRNA nor 3 ' half-molecules. Rather, in the presence of endonuclease or endonuclease plus ligase, a species which comigrated by size with $5^{\prime}$ half-molecules was generated. Additionally, a family of new bands was observed which migrated in a position consistent by size with "two-thirds" molecules. By inference, these molecules would contain all or part of the IVS and the 3'-half of the precursor.

Suppressor function of SUP53 and intron mutants in vivo. The observed in vitro base modifications and splicing behavior of these mutants were correlated with their ability to suppress a nonsense mutation in vivo. $S$. cerevisiae SL183-21C was transformed with DNA containing the SUP53 or mutant allele and the LEU2 marker on a single restriction fragment (Fig. 2). Transformants were initially selected for acquisition of the $L E U 2$ marker. The $\mathrm{Leu}^{+}$ transformants were secondarily tested for their ability to suppress the $\operatorname{trpl-I(Am)~marker~by~growth~on~minimal~}$ medium minus tryptophan. Cells were spotted on tryptophan drop-out plates at different cell densities. Suppressor function was quantified by the lowest cell density at which growth was observed. At all cell densities tested, no growth was seen with the parent SL183-21C cells (Table 2).

Cells receiving the intact SUP53 gene grew in the absence of tryptophan at all densities tested (as few as 10 cells plated), indicating efficient suppression of the amber mutation. Four mutants (ACBP, $\Delta 5^{\prime}$ IVS, Alu5 $\rightarrow 3$, and $\Delta I V S$ ) grew only at significantly higher cell densities (1,000 cells), indicating inefficient suppression of the amber mutation. These four mutants all lacked the wobble base 5-methylcytosine modification found in SUP53 in vitro. The two intron-containing mutants whose precursors could not be spliced ( $\Delta 3^{\prime}$ IVS and INS) were null suppressors. Therefore, the nonsplicing phenotype in vitro faithfully correlated with disfunction in vivo.

\section{DISCUSSION}

These data confirm that deletion of a tRNA gene IVS results in an altered mature tRNA product (22). Furthermore, they emphasize that any change which perturbs the intron and, in turn, the pre-tRNA is sufficient to render the mature tRNA ${ }^{S U P 53}$ less efficient in its translational function (as assayed by amber suppressor efficiency). Finally, they indicate that the reduced suppressor function is correlated with undermodification of the 5-methylcytosine in the wobble base position of the anticodon.

The suppression of a nonsense codon is critically affected by both the nature of the suppressor tRNA anticodon region and the codon context in the mRNA being translated (37). Since these mutants were assayed with a single nonsense codon [trpl-I(Am) mutation], these different levels of suppression are considered to reflect the anticodon modification. The 5-methylcytosine modification is apparently necessary for optimal anticodon-codon pairing. A number of studies have shown that a base change in or undermodification of the wobble base severely alters the translational efficiency of a tRNA $(8,58$; T. G. Hagervall, Ph.D. thesis, University of Umea, Umea, Sweden, 1984). Modifications can both restrict and increase the wobble base pairing capacity $(38,54)$.

As noted in the Results section, the $\mathrm{C}_{48}$ modification (normally a 5-methyl-C; Fig. 1) was not clearly detected in any RNA in vitro. However, lack of the modification at this position is unlikely to have a direct effect on anticodoncodon interactions. There is only one clear example of a suppressor tRNA whose functionality is correlated with a change not in the anticodon or anticodon stem-loop region: the $E$. coli tRNA ${ }^{\text {Trp }}$ UGA suppressor arises by a single base change in the D stem (18).

Since base modifications have not been found to be critical to the secondary or tertiary structure of a tRNA (25), the down-suppressor phenotype of these mutants is probably due to the absence of wobble base modification. Inherent in this interpretation is the assumption that the altered pretRNAs, which are end-processed and spliced in vitro, are appropriately processed beyond the precursor stage, including the addition of base modifications, and produce stable cytoplasmic tRNAs in vivo. Critical to this point would be undermodification of the hypermodified base position (1 base $3^{\prime}$ of the anticodon). The hypermodification of this base has been implicated as critical to codon-anticodon interaction (4, 12) and its undermodification results in an antisuppressor phenotype $(20,29)$. However, all of the functional mutants showed the same level of suppression as the $\Delta$ IVS mutant, which contained the appropriate modification of this position (Fig. 7).

Nucleotide modifications are added on a specific tRNA processing intermediate $(35,41)$. The data presented here illustrate that the enzymes which modify tRNA ${ }^{\text {SUPS3 }}$ fall into three classes: those which are insensitive to the presence or absence of an IVS; those which are dependent on precursor structure (including the presence of an intact IVS); and those which recognize only the mature tRNA species (lacking an IVS).

The modifications made regardless of the presence or nature of an IVS are among those which are highly conserved in eucaryotic tRNAs (2,2-dimethyl- $G_{27}, T_{54}$, and $\left.\psi_{39,55}\right)$. The enzymes which effect these modifications must be recognizing the cloverleaf structure maintained in the presence and absence of an IVS. As noted by McClain and Seidman (34), this constancy of the cloverleaf structure 
eliminates the need for a multiplicity of enzymes for different tRNAs. Furthermore, mutants which disturb conserved structure would not be recognized as appropriate substrates, preventing the production of deleterious RNAs.

The two expected 5-methylcytosine modifications exemplify activities which are apparently sensitive to the structure of the precursor tRNA. The anticodon modification was only found in the intact precursor. Previous studies have shown that the rather conserved 5-methylation of $\mathrm{C}_{48}$ was introduced on unspliced pre-tRNAs $(23,41)$. However, the 12 yeast tRNAs which contained this position 48 cytosine modification included both IVS- and non-IVS-containing species (55). This suggests either that a single methylase, insensitive to the presence of an intron, effects this modification or that multiple methyltransferases are involved.

Our inability to detect methylation of $\mathrm{C}_{48}$ in vitro strengthens the evidence for multiple enzymes which effect the same modification in a single tRNA. Similar results were seen by Keith et al. (24) with a partially purified 5-methyl-C synthase from HeLa cells. Using yeast and $E$. coli tRNA $^{\text {Phe }}$ as substrates, they found that this enzyme methylated $\mathrm{C}_{48}$ and $\mathrm{C}_{49}$ in both RNAs. However, an expected 5-methylation of a cytosine in the anticodon stem was not made. They noted that the methylated cytosines lay in a similar primary sequence, indicating that the methyltransferases that modify tRNAs may have very specific substrate recognition, including primary RNA sequence.

The final class of modifications found in tRNA ${ }^{\text {SUP53 }}$ were those found only in mature tRNA, as exemplified by $\triangle I V S$ RNA. Since these modifications were made on a mature tRNA independent of its production by splicing, these two tRNA maturation steps must not be linked obligatorily in the production of an intron-containing tRNA. The ribose methylation of $G_{18}$ and the 1-methylation of $G_{37}$ (hypermodified base position) are well documented as being dependent on mature structures $(17,41,48)$. Furthermore, $\psi_{32}$ was found only in $\triangle I V S$ RNA, in contrast to the presence of other pseudouridylations $\left(\psi_{32,55}\right)$ in all RNAs examined. Multiple pseudouridine synthases have been documented in other systems $(13,22)$. Finally, the relatively conserved $2-$ methyl-G $_{10}$ was detected only in mature tRNA ${ }^{S U P 53}$. In Xenopus laevis oocytes, Nishikura and DeRobertis (41) found that 2-methyl-G was made on pre-tRNA ${ }^{\text {Tyr }}$. Whether this is another example of multiple enzyme activities or reflects the difference in analyzing the modification pattern in a homologous rather than heterologous system is unclear.

These data clearly illustrate that significant changes can be made in an intron without affecting the absolute ability of the precursor to be spliced. Johnson et al. (21) and Raymond and Johnson (46) showed that several small insertions into and deletions of the yeast tRNA ${ }_{3}^{\mathrm{Leu}}$ intron did not impair transcription, end-processing, and splicing in yeast extract or $X$. laevis oocytes. The efficiency of splicing decreased with increased size of the insertion, and RNAs with large insertions were neither end-processed nor spliced, suggesting that larger changes are significantly perturbing the overall structure of the precursor RNA. In contrast, the smaller insertions and deletions apparently preserved the basic intron and, more importantly, the precursor structure.

Of the SUP53 intron mutants examined here, only one ( $\Delta 3^{\prime}$ IVS) was refractory to the splicing enzymes. This mutant precursor RNA was poorly recognized by other tRNA maturation enzymes whose activities remove $5^{\prime}$ and $3^{\prime}$ extensions from the primary transcript. By analogy to other mutants $(2,26-28,33,42,44,59)$, this pre-tRNA must not conform to an appropriate precursor secondary or tertiary structure.

A computer-generated secondary structure for $\Delta 3^{\prime}$ IVS RNA suggests that this precursor does not form a $D$ stem or loop, but an intron sequence can base-pair to D stem-loop nucleotides. Numerous studies have shown that alteration of D stem-loop sequence or structure affects end-processing and splicing of precursor tRNAs $(2,27,33,39,44)$. Additional changes in the $\Delta 3^{\prime}$ IVS intron sequence which disrupted the capacity to form this aberrant secondary structure partially rescued the nonprocessed, nonspliced phenotype (data not shown).

The results of nuclease sensitivity (30) and chemical modification (57) studies of RNA structure are consistent with the existence of base-pairing between the anticodon and a complementary intron sequence in $S$. cerevisiae pretRNAs. As noted by Ogden et al. (43), such secondary structure is not necessarily found in pre-tRNAs from other organisms. Several intron-containing precursors from Schizosaccharomyces pombe which do not exhibit this complementarity are inefficiently spliced in $S$. cerevisiae extracts $(11,56)$. Therefore, since this structure is invariant among the nine $S$. cerevisiae precursors $(30,43,57)$, it was assumed to be important for recognition by the homologous splicing machinery. However, the ACBP and $\Delta 5^{\prime}$ IVS mutants, which have a disruption and a deletion, respectively, of the complementary region, were cut and ligated by the yeast tRNA endonuclease and ligase (Fig. 8). Thus, there is no absolute requirement for this particular secondary structure for recognition by the enzymes.

Neither the $\Delta$ IVS nor the INS mutant RNAs were spliced. These results are not surprising since mature tRNAs are not substrates for, and in fact appear to inhibit, endonuclease activity (P. Green and J. Abelson, unpublished observation). Clearly, the insertion of a 2-base intron, as exemplified by the INS mutant, was insufficient to define this RNA as a precursor. The smallest intron known to be excised (inefficiently) by $S$. cerevisiae enzymes is 8 nucleotides long ( $S$. pombe pre-tRNA ${ }^{\text {Lys }}$ [11]). Further studies must be done to elucidate the lower limit of size or structure sufficient for endonuclease recognition.

The tRNA ligase protein has been purified, its gene cloned (45a), and its mechanism of action defined (16, 45a). However, the integral-membrane-bound endonuclease has defied complete purification (45; P. Green and J. Abelson, unpublished observation). Until the highly purified enzyme is available, the precise interaction between endonuclease and its precursor tRNA substrate cannot be elucidated. However, the $\Delta 3^{\prime}$ IVS mutant RNA, which was refractory to complete cleavage by endonuclease did exhibit inefficient, partial cleavage. This mutant RNA generated some $5^{\prime}$ halfmolecules and presumptive two-thirds molecules (IVS plus 3 '-half; see Fig. 8). Since the $5^{\prime}$ splice junction lay in a constant position in all of the precursors, it is tempting to speculate that this junction is more easily recognized and cut by endonuclease than the $3^{\prime}$ junction.

Finally, none of the mutant precursor tRNAs contained the full complement of base modifications found in the SUP53 precursor (Table 1), yet most of these precursors were successfully spliced. These data suggest that base modifications, which play no defined role in maintenance of tRNA structure, are not required for splicing to occur. Recently, the yeast pre-tRNA ${ }^{\text {Phe }}$ has been synthesized in vitro from a $\mathrm{T} 7$ bacteriophage promoter by the cognate RNA polymerase. This totally unmodified precursor tRNA is efficiently cut and ligated by the $S$. cerevisiae en- 
zymes in vitro (V. Reyes and J. Abelson, unpublished observation).

\section{ACKNOWLEDGMENTS}

We thank Andy Newman, Peter Johnson, Chris Greer, and Eric Phizicky for their advice and encouragement; Zenaida Resplandor for technical assistance; and Linda Brubaker, Connie Katz, and Donna Walker for preparation of the manuscript.

This work was supported by American Cancer Society grant ACS NP302D and Public Health Service grant GM-32637 from the National Institutes of Health to J.A. M.C.S. was supported by a Public Health Service Genetics Training Grant (Biology Department, University of California, San Diego).

\section{LITERATURE CITED}

1. Andreadis, A., Y.-P. Hsu, G. B. Kohlhaw, and P. Schimmel. 1982. Nucleotide sequence of yeast LEU2 shows 5'-non-coding region has sequences cognate to leucine. Cell 31:319-325.

2. Baldi, M. I., E. Mattoccia, and G. P. Tocchini-Valentini. 1983. Role of RNA structure in splicing: excision of the intervening sequence in yeast tRNA ${ }^{\mathrm{Leu}}{ }_{3}$ is dependent on the formation of a D stem. Cell 35:109-115.

3. Birnboim, H. C., and J. Doly. 1979. A rapid alkaline extraction procedure for screening recombinant plasmid DNA. Nucleic Acids Res. 7:1513-1523.

4. Bjork, G. R. 1984. Modified nucleosides in RNA-their formation and function, p. 291-330. In D. Apirion (ed.), Processing of RNA. CRC Press, Boca Raton, Fla.

5. Bolivar, F., and K. Backman. 1979. Plasmids of Escherichia coli as cloning vectors. Methods Enzymol. 68:245-267.

6. Brown, A., C.-J. Pan, and W. F. Marzluff. 1982. Methylation of ribonucleic acid in a cell-free system from mouse myeloma cells. Biochemistry 21:4303-4310.

7. Cech, T. R. 1983. RNA splicing: three themes with variations. Cell 34:713-716.

8. Colby, D. S., P. Schedl, and C. Guthrie. 1976. A functional requirement for modification of the wobble nucleotide in the anticodon of a suppressor tRNA. Cell 9:449-463.

9. Engelke, D. R., P. Gegenheimer, and J. Abelson. 1985. Nucleolytic processing of a tRNA ${ }^{\text {Arg }}$-tRNA ${ }^{\text {Asp }}$ dimeric precursor by a homologous component from Saccharomyces cerevisiae. J. Biol. Chem. 260:1271-1279.

10. Fischoff, D. A., R. H. Waterston, and M. V. Olson. 1984. The yeast cloning vector YEp13 contains a tRNA ${ }^{\mathrm{Leu}_{3}}$ gene that can mutate to an amber suppressor. Gene 27:239-251.

11. Gamulin, V., J. Mao, B. Appel, M. Sumner-Smith, F. Yamao, and D. Soll. 1983. Six Schizosaccharomyces pombe tRNA genes including a gene for a tRNA ${ }^{\text {Lys }}$ with an intervening sequence which cannot base-pair with the anticodon. Nucleic Acids Res. 11:8537-8546.

12. Gefter, M. L., and R. L. Russell. 1969. Role of modifications in tyrosine transfer RNA: a modified base affecting ribosome binding. J. Mol. Biol. 39:145-157.

13. Green, C. J., H. O. Kammen, and E. E. Penhoet. 1982. Purification and properties of a mammalian tRNA pseudouridine synthase. J. Biol. Chem. 257:3045-3052.

14. Greer, C. L., and J. A. Abelson. 1984. RNA splicing: rearrangement of RNA sequences in the expression of split genes. Trends Biochem. Sci. 4:139-141.

15. Greer, C. L., B. Javor, and J. Abelson. 1983. RNA ligase in bacteria: formation of a $2^{\prime}, 5^{\prime}$ linkage by an $E$. coli extract. Cell 33:899-906.

16. Greer, C. L., C. L. Peebles, P. Gegenheimer, and J. Abelson. 1983. Mechanism of action of a yeast RNA ligase in tRNA splicing. Cell 32:537-546.

17. Guthrie, C., J. G. Seidman, S. Altman, B. G. Barrell, J. D. Smith, and W. H. McClain. 1973. Identification of tRNA precursor molecules made by phage T4. Nature (London) New Biol. 246:6-11.

18. Hirsh, D. 1971. Tryptophan transfer RNA as the UGA suppressor. J. Mol. Biol. 58:439-458.
19. Ito, H., Y. Fukada, K. Murata, and A. Kimura. 1983. Transformation of intact yeast cells treated with alkali cations. J. Bacteriol. 153:163-168.

20. Janner, F., G. Vogeli, and R. Fluri. 1980. The antisuppressor strain sin-1 of Schizosaccharomyces pombe lacks the modification isopentenyladenosine in transfer RNA. J. Mol. Biol. 139:207-219.

21. Johnson, J. D., R. Ogden, P. Johnson, J. Abelson, P. Dembeck, and K. Itakura. 1980. Transcription and processing a yeast tRNA gene containing a modified intervening sequence. Proc. Natl. Acad. Sci. USA 77:2564-2568.

22. Johnson, P. F., and J. Abelson. 1983. The yeast tRNA ${ }^{\mathrm{Tyr}}$ gene intron is essential for correct modification of its tRNA product. Nature (London) 303:681-687.

23. Kang, H. S., R. C. Ogden, G. Knapp, C. L. Peebles, and J. Abelson. 1979. Structure of yeast tRNA precursors containing intervening sequences, p. 69-84. In R. Axel, T. Maniatis, and F. Fox (ed.), Eukaryotic gene regulation. Academic Press, Inc., New York.

24. Keith, J. M., E. M. Winters, and B. Moss. 1980. Purification and characterization of a $\mathrm{HeLa}$ cell transfer RNA (cytosine-5-)methyltransferase. J. Biol. Chem. 255:4636-4644.

25. Kim, S.-H. 1979. Crystal structure of yeast tRNA ${ }^{\text {Phe }}$ and general structural features of other tRNAs, p. 83-100. In P. R. Schimmel, D. Soll, and J. N. Abelson (ed.), Transfer RNA: structure, properties, and recognition. Cold Spring Harbor Laboratory, Cold Spring Harbor, N.Y.

26. Koski, R. A., S. G. Clarkson, J. Kurjan, B. D. Hall, and M. Smith. 1980. Mutations of the yeast SUP4 tRNA ${ }^{\text {Tyr }}$ locus: transcription of the mutant genes in vitro. Cell 22:415-425.

27. Koski, R. A., M. Worthington, D. S. Allison, and B. D. Hall. 1982. An in vitro RNA polymerase III system from $S$. cerevisiae: effects of deletions and point mutations upon SUP4 gene transcription. Nucleic Acids Res. 10:8127-8143.

28. Kurjan, J., B. D. Hall, S. Gillam, and M. Smith. 1980. Mutations at the yeast SUP4 tRNA ${ }^{\text {Tyr }}$ locus: DNA sequence changes in mutants lacking suppressor activity. Cell 20:701-709.

29. Laten, J., J. Gorman, and R. M. Bock. 1980. Isopentenyladenosine deficient tRNA from an antisuppressor mutant of Saccharomyces cerevisiae. Nucleic Acids Res. 5:4329-4342.

30. Lee, M.-C., and G. Knapp. 1985. Transfer RNA splicing in Saccharomyces cerevisiae: secondary and tertiary structures of the substrates. J. Biol. Chem. 260:3108-3115.

31. Liebman, S. W., Z. Srodulski, C. R. Reed, J. W. Stewart, F. Sherman, and G. Brennan. 1984. Yeast amber suppressors corresponding to tRNA ${ }^{\mathrm{Leu}}{ }_{3}$ genes. J. Mol. Biol. 178:209-226.

32. Maniatis, T., E. F. Fritsch, and J. Sambrook. 1982. Molecular cloning: a laboratory manual. Cold Spring Harbor Laboratory, Cold Spring Harbor, N.Y.

33. Mattocia, E., M. I. Baldi, G. Pande, R. Ogden, and G. TocchiniValentini. 1983. Mutations in the A block of the yeast tRNA ${ }^{\mathrm{Leu}_{3}}$ gene that allows transcription but abolishes splicing and 5' end maturation. Cell 32:67-76.

34. McClain, W. H., and J. G. Seidman. 1975. Genetic perturbations that reveal tertiary conformation of tRNA precursor molecules. Nature (London) 257:106-110.

35. Melton, D. A., E. M. DeRobertis, and R. Cortese. 1980. Order and intracellular location of the events involved in maturation of a spliced tRNA. Nature (London) 284:143-148.

36. Miller, J. H. 1972. Experiments in molecular genetics. Cold Spring Harbor Laboratory, Cold Spring Harbor, N.Y.

37. Miller, J. H., and A. M. Albertini. 1983. Effects of surrounding sequence on the suppression of nonsense codons. J. Mol. Biol. 164:59-71.

38. Mitra, S. K., F. Lustig, B. Akesson, U. Lagerkvist, and L. Strid. 1977. Codon-anticodon recognition in the valine codon family. J. Biol. Chem. 252:471-478.

39. Newman, A. J., R. C. Ogden, and J. Abelson. 1983. tRNA gene transcription in yeast: effects of specified base substitutions in the intragenic promoter. Cell 35:117-125.

40. Ng, R., H. Domdey, G. Larson, J. J. Rossi, and J. Abelson. 1985. A test for intron function in the yeast actin gene. Nature (London) 314:183-184. 
41. Nishikura, K., and E. M. DeRobertis. 1981. RNA processing in microinjected Xenopus oocytes. Sequential addition of base modifications in a spliced transfer RNA. J. Mol. Biol. 145:405-420.

42. Nishikura, K., J. Kurjan, B. D. Hall, and E. M. DeRobertis. 1982. Genetic analysis of the processing of a spliced tRNA. EMBO J. 1:263-268.

43. Ogden, R. C., M.-C. Lee, and G. Knapp. 1984. Transfer RNA splicing in Saccharomyces cerevisiae: defining the substrates. Nucleic Acids Res. 12:9367-9382.

44. Pearson, D., I. Willis, H. Hottinger, J. Bell, A. Kumar, U. Leupold, and D. Soll. 1985. Mutations preventing expression of sup3 tRNA ${ }^{\text {Ser }}$ nonsense suppressors of Schizosaccharomyces pombe. Mol. Cell. Biol. 5:808-815.

45. Peebles, C. L., P. Gegenheimer, and J. Abelson. 1983. Precise excision of intervening sequences from precursor tRNAs by a membrane-associated yeast endonuclease. Cell 32:525-536.

45a.Phizicky, E., R. Schwartz, and J. Abelson. 1986. S. cerevisiae tRNA ligase: purification of the protein and isolation of the structural gene. J. Biol. Chem. 261:2978-2986.

46. Raymond, G., and J. D. Johnson. 1983. The role of non-coding DNA sequences in transcription and processing of a yeast tRNA. Nucleic Acids Res. 11:5969-5988.

47. Rothstein, R. J. 1983. One-step gene disruption in yeast. Methods Enzymol. 101:202-212.

48. Sakano, H., Y. Shimura, and H. Ozeki. 1974. Selective modification of nucleosides of tRNA precursors accumulated in a temperature-sensitive mutant of Escherichia coli. FEBS Lett. 48:117-121.

49. Saneyoshi, M., Z. Ohashi, F. Harada, and S. Nishimura. 1972. Isolation and characterization of 2-methyladenosine from Escherichia coli $\mathrm{tRNA}^{\mathrm{Glu}}{ }_{2}, \mathrm{tRNA}^{\mathrm{Asp}}{ }_{1}, \mathrm{tRNA}^{\mathrm{His}}{ }_{1}$ and $\mathrm{tRNA}^{\mathrm{Arg}}$. Biochim. Biophys. Acta 262:1-10.

50. Sanger, F., S. Nicklin, and A. R. Coulson. 1977. DNA sequenc- ing with chain-terminating inhibitors. Proc. Natl. Acad. Sci. USA 74:5463-5467.

51. Sharp, P. 1985. On the origin of RNA splicing and introns. Cell 42:397-400.

52. Shaw, K. J., and M. V. Olson. 1984. Effects of altered 5'flanking sequences on the in vivo expression of a Saccharomyces cerevisiae tRNA ${ }^{\mathrm{Tyr}}$ gene. Mol. Cell. Biol. 4:657-665.

53. Sherman, F., G. R. Fink, and J. B. Hicks. 1983. Methods in yeast genetics: laboratory manual. Cold Spring Harbor Laboratory, Cold Spring Harbor, N.Y.

54. Sherman, F., B. Ono, and J. R. Stewart. 1979. Use of the iso-1-cytochrome $\mathrm{C}$ system for investigating nonsense mutants and suppressors in yeast, p. 133-153. In J. E. Celis and J. D. Smith (ed.), Nonsense mutations and tRNA suppressors. Academic Press, Inc., London.

55. Sprinzl, M., J. Moll, F. Meissner, and T. Hartman. 1985. Compilation of tRNA sequences. Nucleic Acids Res. 13:r1-r49.

56. Sumner-Smith, M., H. Hottinger, I. Willis, T. L. Koch, R. Arentzen, and D. Soll. 1984. The sup8 tRNA ${ }^{\text {Leu }}$ gene of Schizosaccharomyces pombe has an unusual intervening sequence and reduced pairing in the anticodon stem. Mol. Gen. Genet. 197:447-452.

57. Swerdlow, H., and C. Guthrie. 1984. Structures of introncontaining tRNA precursors: analysis of solution conformation using chemical and enzymatic probes. J. Biol. Chem. 259:5197-5207.

58. Weissenbach, J., and G. Dirheimer. 1978. Pairing properties of the methylester of 5-carboxymethyl uridine in the wobble posi-

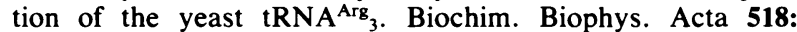
530-534.

59. Willis, I., H. Hottinger, D. Pearson, V. Chisholm, U. Leupold, and D. Soll. 1984. Mutations affecting excision of the intron from a eukaryotic dimeric tRNA precursor. EMBO J. 3:15731580 . 